\title{
Development and characterization of a gelatin-based coating with unique sealing properties
}

\begin{tabular}{|r|l|}
\hline Journal: & Journal of Applied Polymer Science \\
\hline Manuscript ID: & APP-2010-01-0262.R1 \\
\hline Wiley - Manuscript type: & Research Article \\
\hline Keywords: & failure, poly(propylene) (PP), electron microscopy \\
\hline & \\
\end{tabular}

\section{S ScholaroNE \\ Manuscript Central}




\section{Development and characterization of a gelatin-based coating with unique sealing properties}

Stefano Farris ${ }^{*}$, Carlo A. Cozzolino, Laura Introzzi, Luciano Piergiovanni

Department of Food Science and Microbiology - Packaging laboratory

University of Milan Via Celoria, 2 - 20133 Milan, Italy

Fax: +39 0250316672; E-mail: stefano.farris@ unimi.it

*Correspondence to: S. Farris (stefano.farris@unimi.it)

John Wiley ${ }^{-1}$ - - Sons, Inc. 
ABSTRACT: The experimental results on the development of thin $(\sim 1.5 \mu \mathrm{m})$ gelatin-based coatings and the investigation on their sealing attribute when applied onto oriented polypropylene (OPP) are reported. The sealing performance, expressed as the strain energy required to separate the sealed joints, was studied as a function of three different influencing factors. $\mathrm{pH}$ of the hydrogel solution was varied between 5 and 11. The highest seal strength values were obtained for $\mathrm{pH}$ values beyond the isoelectric point (IEP) of the gelatin molecule. The effect of the plasticizer (glycerol) was studied by changing its concentration from 2.5 wt.$\%$ to 7.5 wt.- $\%$ to the total weight of the hydrogel solution. Glycerol concentration $=7.5$ wt.$\%$ was found to be the best for achieving adequate strain energy values. The influence of a hydrophobic component on the capability of the coating to act as a sealant has also been assessed. The hydrophobic component had a positive effect only up to a certain level (1 wt.$\%$, weight percent), whereas beyond this value it affected the seal strength attribute. According to the best setting conditions, seal strength values for the OPP biocoated films of approximately $61 \mathrm{Nx} \mathrm{mm} \mathrm{were} \mathrm{attained,} \mathrm{with} \mathrm{a} \mathrm{corresponding} \mathrm{maximum} \mathrm{force} \mathrm{required} \mathrm{to}$ break the joints of $2.4 \mathrm{~N}$. These results are discussed by taking into consideration the modality of seals opening. Interestingly, the heat-seal (temperature: $90^{\circ} \mathrm{C}$; dwell time: $1 \mathrm{~s}$; pressure: 4 bar) failed in both peeling and tearing mode failure, as confirmed by microscopy, spectrophotometric and particle size analyses.

Key words: DSC; failure; heat-seal strength; poly(propylene) (PP); SEM 


\section{INTRODUCTION}

The use of thin polymeric coatings encompasses different fields like automotive, medical/pharmaceutical, marine, photography, packaging, textile, army and architecture, where they find application as adhesives, protective barriers, slip/anti-slip agents, conductors, decorations, inks and paints. ${ }^{1}$ The packaging sector, accounting for several branches like food, pharmaceutical, biomedical, health-care, etc., is a major field of application of coatings, either to improve bulk properties of their substrates like barrier, ${ }^{2}$ optical, ${ }^{3}$ mechanical, ${ }^{4}$ thermal, ${ }^{5}$ anticorrosion, ${ }^{6}$ sealing, ${ }^{7}$ or to add new features such the antimicrobial activity. ${ }^{8}$ To this purpose, polymers of synthetic origin have predominantly been used so far, being the most practical, economical, and useful solution for packaging applications, principally due to their low cost and ready availability.

Only recently it has been expressed an increasing interest towards new formulations originating from natural and renewable resources, ${ }^{9}$ not only due to the increase in the price of crude oil but also because of other established advantages mostly related to their versatile nature and chemical structure. In addition, biobased coatings have been indicated as a promising way to face the waste disposal issue. ${ }^{10}$ Biobased coatings made of whey protein isolate (WPI) have been credited of both excellent transparency ${ }^{11}$ and barrier properties against oxygen; ${ }^{12}$ it has also been outlined the great potential of coatings made of soy protein isolate (SPI) as an efficient carrier of bioactive compounds (e.g., antimicrobials); ${ }^{13}$ polyolefins coated with a natural slip agent (acetic acid esters) added to a protein matrix showed improved frictional properties $;{ }^{14}$ chitosan has been proved to be effective as a coating material on paper and paperboard ${ }^{15}$ and for producing biopolymer coated polypropylene films with biocidal activity. ${ }^{16}$ Among biopolymers, gelatin has been widely used due to its multifaceted nature. Filmogenic and foam behavior, good barrier properties against oxygen, and transparency, besides abundance and relatively low cost, justified its use for many different purposes. Indeed, gelatin found application to produce new high-performance 
biodegradable laminates, ${ }^{17}$ for manufacturing antimicrobial edible films, ${ }^{18}$ to fabricate wound dressing, ${ }^{19}$ and as soft capsules. ${ }^{20}$

Of late, gelatin-based coatings have been formulated in the attempt of exploiting its ancient feature, i.e. the adhesive property, which allowed obtaining the earliest glues in the New Stone Age. ${ }^{21}$ The adhesive properties of gelatin, credited to be responsible for the adhesion properties of such a biopolymer, can be ascribed to its inherent chemical structure, accounting for polar and/or chargeable functional groups such as hydroxyl $(\mathrm{OH})$, carboxylic acid $(\mathrm{COOH})$ and aminic $\left(\mathrm{NH}_{2}\right)$ along its molecular backbone, ${ }^{22}$ as shown in Figure 1. The functionality of these groups, and thereby of the whole macromolecule, is strongly influenced by external factors such as $\mathrm{pH}$ and ionic strength. In our previous work, ${ }^{23}$ we studied the influence of the most relevant process variables (i.e., the temperature of the sealing bars, the pressure exerted by the bars during the seal process and the dwell time) on the seal strength of a heat-sealed gelatin-based coating coupled to a plastic substrate. We demonstrated that, unlike the conventional heat sealant thermoplastic films, the factor influencing the seal strength the most is the bars pressure rather than temperature and time. Nevertheless, the effect relying on the key-formulation factors has not been quantified so far. Therefore, also in the attempt to provide further information on the development of bio-based functional coatings, this work aimed at: 1) understanding the effect of the components used in the coating formulation as well as the influence of the $\mathrm{pH}$ of the hydrogel solution on the seal strength of coated polypropylene strips; 2) pinpointing adequate sealing performance that can profitably used in practical applications, such as the sealing of plastic surfaces; 3) providing an exhaustive explanation towards the mode of failure underlying the physics of the heat-seal separation. 


\section{EXPERIMENTAL}

\section{Coating preparation}

Type A, 133 Bloom, pharmaceutical and food grade pigskin gelatin powder (Weishardt International, Grauliet Cedex, France), acetic acid esters produced from monoglycerides (Grindsted ${ }^{\circledR}$ Acetem 70-00 P, Danisco A/S, Langebrogade, Denmark), glycerol (Giomavaro, Brugherio, Italy) and milli-Q water (18.3 M $\Omega)$ were used as received for the hydrogel solutions preparation. The bio-coated plastic films were prepared according to the procedure protected by international patent WO 2008/075396 A1 ${ }^{24}$ Briefly, the gelatin-glycerol mix was first heated to $60^{\circ} \mathrm{C}$ in order to obtain a complete solubilization and denaturation of the protein. When necessary, the $\mathrm{pH}$ was adjusted using sodium hydroxide (Fluka Sigma-Aldrich Chemie, Germany) 1M. At this point, the lipid component was added and mixed for 2 min with a homogenizer (IKA®-Werke, Staufen, Germany), at the speed of $24000 \mathrm{rpm}$. The different hydrogel solutions were obtained by varying the $\mathrm{pH}$ between 5 and 11 . The glycerol content was varied between $2.5 \mathrm{wt} .-\%$ and $7.5 \mathrm{wt} .-\%$ on the total weight of the water hydrogel solution. The lipid concentration was varied between $1 \mathrm{wt} .-\%$ and $3 \mathrm{wt} .-\%$. The amount of gelatin in the final slurry was kept constant at $10 \mathrm{wt.} . \%$, which has been previously suggested for a proper deposition of the coating on the plastic substrate. ${ }^{14}$ The gelatin-based solutions so obtained were poured on the corona-treated side $(24 \mathrm{x} 18 \mathrm{~cm})$ of oriented polypropylene films (Radici Film, S. Giorgio di Nogaro, Italy) $20 \pm 0.5 \mu \mathrm{m}$ thick, with an automatic applicator (Ref. 1137, Sheen Instuments, Kingston, UK) equipped with a steel horizontal rod to obtain a wet coating thickness of approximately $10 \mu \mathrm{m}$ (data provided by the factory). Coating deposition was performed according to ASTM D823-07 - Practice C ${ }^{25}$ at a constant speed of $150 \mathrm{~mm} \mathrm{~min}^{-1}$. Coated films were dried using a constant and perpendicular flux of mild air $\left(25 \pm 0.3^{\circ} \mathrm{C}\right.$ for $\left.2 \mathrm{~min}.\right)$ at distance of $40 \mathrm{~cm}$ from the applicator, and then stored under 
controlled conditions $\left(23 \pm 0.5^{\circ} \mathrm{C}, 40 \pm 2.0 \% \mathrm{RH}\right)$ for $24 \mathrm{~h}$. At least five replicates for each sample were used for the analyses.

\section{Characterization techniques}

\section{Thickness determination}

The thickness of the uncoated plastic films was measured with a micrometer (Dialmatic DDI030M, Bowers Metrology, Bradford, UK) to the nearest $0.001 \mathrm{~mm}$ at 10 different random locations. For the determination of the thickness of the biodegradable layers coated on the plastic films, a $10 \times 10 \mathrm{~cm}$ sample was cut and weighed $\left(\mathrm{M}_{1}\right)$. The coating was mechanically removed using hot water $\left(80^{\circ} \mathrm{C}\right)$ and the resulting base film weighed $\left(\mathrm{M}_{2}\right)$. The apparent thickness of the coating was obtained using the following equation: ${ }^{26}$

$1=\left[\left(M_{1}-M_{2}\right) / \rho\right] \times 100$

where $M_{1}$ is the unit total mass (plastic film and coating), $M_{2}$ is the unit mass of the plastic film $\left(\mathrm{g} \mathrm{dm}^{-2}\right), \rho$ is the density of the aqueos solution $\left(\mathrm{g} \mathrm{cm}^{-3}\right), 1$ is the thickness $(\mu \mathrm{m})$, being known $\mathrm{M}_{1}-\mathrm{M}_{2}$ and $\rho$.

\section{Seal strength determination}

Strips of $2.54 \mathrm{~cm}$ wide and $15 \mathrm{~cm}$ long were obtained using a precision sample cutter (mod. MMT, Thwing-Albert, West Berlin, NJ, USA). Two strips at a time were placed on top of one another, and an area of $2.54 \times 1.5 \mathrm{~cm}$ was heat sealed using a thermal heat sealer Polikrimper TX/08 (Alipack, Pontecurone, Italy) provided by smooth bars. Temperature, pressure and dwell time of the sealing bars were kept constant respectively at $90^{\circ} \mathrm{C}, 4$ bar and $1 \mathrm{sec}$, which were proved to be the best experimental setting conditions. ${ }^{23}$ Sealed samples were kept for $24 \mathrm{~h}$ at $23 \pm 0.5^{\circ} \mathrm{C}$ and $50 \pm 2.0 \% \mathrm{RH}$ in a climatic chamber in order to achieve chemical stabilization before testing. Seal strength expressed as strain energy ( $\mathrm{N} \mathrm{x} \mathrm{mm)} \mathrm{was}$ measured through the so-called T-peel test according to the standard method as described by ASTM F $88 \mathrm{M}-09^{27}$ by means of a dynamometer (mod. Z005, Zwick Roell, Ulm, Germany) 
fitted with a $100 \mathrm{~N}$ load cell and connected to two clamps placed at a distance of $10 \mathrm{~cm}$ one from the other. Each run was performed at a crosshead speed of $300 \mathrm{~mm} \mathrm{~min}^{-1}$.

\section{SEM analysis}

Morphological investigation of the surface of the coated plastic films after joints breakage was performed in order to achieve more detailed information on the mode of failure of the seal. Strips of dry film were immersed in liquid Nitrogen for 5 minutes and then cross fractured manually using cold tweezers. The dried fragments were glued to specimen stubs, sputter-coated with a thin layer of gold and examined with a Phenom ${ }^{\mathrm{TM}}$ scanning electron microscope (FEI Co., Inc., Hillsboro, OR). At least 10 images were collected for each sample.

\section{Particle size measurement}

The mean particle size of the biopolymer systems was determined using a commercial dynamic light scattering instrument (Zetasizer NanoZS, Malvern Instruments, Worcestershire, United Kingdom). Based on measurements of the Brownian motion of the particles in the solution, the z-average diameters $\left(\mathrm{s}_{\mathrm{z}}\right)$ of the particles were determined using the StokesEinstein equation. All measurements were made on at least two freshly prepared undiluted samples at $40^{\circ} \mathrm{C}$, i.e. the temperature at which the coating hydrogel solution is spread on the plastic substrate.

\section{Thermal analysis}

Differential scanning calorimetry analysis was performed using a DSC 823 (Mettler Toledo, Columbus, $\mathrm{OH}$ ) supplied by a quench-cooling accessory. Biocoating samples were firstly placed in desiccators containing $\mathrm{CaCl}_{2}$ for two weeks. Approximately $10 \mathrm{mg}$ biocoating samples were then put in a hermetic sealed aluminium pan. With the objective of determining only the melting temperature $\left(\mathrm{T}_{\mathrm{m}}\right)$ of the dry coating, a unique scan from $5{ }^{\circ} \mathrm{C}$ to $110{ }^{\circ} \mathrm{C}$ in an inert environment $\left(100 \mathrm{ml} \mathrm{m^{-1 }} \mathrm{N}_{2}\right)$ at $10{ }^{\circ} \mathrm{C} \min ^{-1}$ was run. The temperature of the 
endothermic peak was taken as the melting temperature, $T_{m}$. It was calculated by the software Star $^{\mathrm{e}}$ version 9.0 (Mettler Toledo, Columbus, $\mathrm{OH}$ ).

\section{Transparency measurement}

Transparency was determined according to ASTM D $1746-88^{28}$ using an UV-Vis spectrophotometer (Lambda 650, PerkinElmer, Waltham, USA) for measurements between 200 and $800 \mathrm{~nm}$. In particular, the transparency of both uncoated and coated films was measured in terms of specular transmittance, i.e. the transmittance value obtained when the transmitted radiant flux includes only the light transmitted in the same direction as that of the incident flux in the range $540-560 \mathrm{~nm}$. Then, the correspondent transparency value was obtained according to the equation:

$\left(\mathrm{T}_{\mathrm{s}}\right)=100 \mathrm{I}_{\mathrm{s}} / \mathrm{I}_{0}$

where $T_{\mathrm{s}}$ is the specular transmittance at $550 \mathrm{~nm}$; $\mathrm{I}_{\mathrm{s}}$ is the light intensity with the specimen in the beam; $I_{0}$ is the light intensity with no specimen in the beam.

\section{RESULTS AND DISCUSSION}

\section{Influence of the pH}

The influence of the $\mathrm{pH}$ on the seal strength attribute of the coating was studied by keeping the glycerol and lipid concentrations at 5 wt.- $\%$ and 2 wt.- $\%$, respectively. The pH value was varied from 5 to 11 . It has been observed (Figure 2) that as the $\mathrm{pH}$ increases, the seal strength, expressed as strain energy, increases from $26.37 \pm 2.3 \mathrm{~N} \mathrm{x} \mathrm{mm}$ to $40.41 \pm 1.56$ $\mathrm{N} \times \mathrm{mm}$. The positive influence of the $\mathrm{pH}$ on the seal strength is likely ascribable to charge distribution reasons. Supposedly, since the isoelectric point (IEP) of the gelatin used in this work ranges from 8.5 to 9.0 , at $\mathrm{pH}=11$ most carboxylic groups, which account for the majority of the charged groups along the gelatin backbone, ${ }^{29}$ are de-protonated (i.e., 
carboxylates). It seems to be beneficial to the seal strength attribute of the gelatin-based coating, due to the established contribute of the $-\mathrm{COO}^{-}$groups to the adhesive properties of gelatin. ${ }^{21}$ In addition, beyond the IEP electrostatic repulsion exists between gelatin molecules, allowing the unfolding of the triple-helix chains. As a consequence, a higher reactivity of the charged groups underlying the seal formation is expected under this $\mathrm{pH}$ value. Therefore, in order to achieve the best sealing performance, the $\mathrm{pH}$ value was fixed at 11 .

\section{Influence of glycerol concentration}

The effect of glycerol concentration was assessed by varying its concentration from 2.5 wt.-\% (17.24 wt.-\% on dry basis) to 7.5 wt.-\% (38.46 wt.-\% on dry basis) and keeping the pH of the solution at 11 and the lipid content at $2 \mathrm{wt} .-\%$. From Figure 2 it is clearly seen that an increase in the glycerol content promotes a proportional increase in the seal strength attribute. More specifically, the strain energy values range from $15.42 \pm 0.74 \mathrm{~N} \mathrm{x} \mathrm{mm}$ to $64.53 \pm 2.68 \mathrm{~N}$ $\mathrm{x} \mathrm{mm}$ as the glycerol concentration moved from the minimum to the maximum values. As known, the effect of glycerol can be explained in terms of free volume theory. ${ }^{30}$ Indeed, such a small molecule acts as a plasticizer, thus filling the gaps especially at intermolecular level. It gives rise to a reduction of the $\mathrm{T}_{\mathrm{g}}$ of the thermoplastic biopolymer (i.e., gelatin), due to a marked increase in the mobility of the polymeric chains, which in turn is provoked by a reduction of the molecular interactions (e.g., hydrogen bonds) between adjacent chains. As a consequence, a deeper interaction (entanglement) between melted molecules is promoted, being constant the setting of the sealing process variables (bars temperature, sealing time and bars pressure). Thus, glycerol $=7.5 \mathrm{wt} .-\%$ (wet basis) was used for further experiments.

\section{Influence of lipid concentration}

To determine the influence of the hydrophobic component used within the coating formulation, the hydrogel solutions were prepared by fixing the $\mathrm{pH}$ and the glycerol concentration at 11 and 7.5 wt.-\%, respectively. The acetic acid esters concentration was 
varied from 1 wt.-\% (5.40 wt.- $\%$ on dry basis) to 3 wt.- $\%$ (14.63 wt.- $\%$ on dry basis). As shown in Figure 2, a double behavior can be observed as the concentration of the lipid component is varied. In particular, from $1 \mathrm{wt} .-\%$ up to $2 \mathrm{wt} .-\%$ there is a slight increase in the strain energy values (from $60.89 \pm 5.16 \mathrm{~N} \mathrm{x} \mathrm{mm} \mathrm{to} 63.28 \pm 4.78 \mathrm{~N} \mathrm{x} \mathrm{mm}$ ), though not statistically significant. The scenario changes completely beyond 2 wt.- $\%$ : the strain energy values drop quickly up to a minimum of $20.79 \pm 2.16 \mathrm{~N} \mathrm{x} \mathrm{mm}$ at $3 \mathrm{wt} .-\%$ concentration. It can be probably explained in terms of dilution effect. As the concentration of the lipid is increased beyond a certain boundary value (i.e., 2 wt.-\%) the strain energy is straightaway suppressed, due to the additive effect of the lipid that, together with the glycerol and the water added for adjusting the $\mathrm{pH}$, acts synergistically as a plasticizer, thus reducing the cohesive energy density of the protein network with a detrimental increase in free volume. ${ }^{14}$ This finding emphasize the importance of the "glycerol-lipid" interaction, which can be indicated as driving force governing the seal strength performance of the biobased coating.

According to the results obtained in this first step, the best heat-sealing bio-coatings in terms of seal strength have been obtained for $\mathrm{pH}$ of the hydrogel solution equal to 11 , glycerol concentration $=7.5$ wt.- $\%$, hydrophobic component amount $=1$ wt.- $\%$, and gelatin concentration $=10 \mathrm{wt} .-\%$. According to this formulation, a strain energy value of $61.12 \mathrm{~N} \mathrm{x}$ $\mathrm{mm}( \pm 5.85)$ was recorded for OPP-biocoated strips, to which corresponded a seal strength of $2.39 \mathrm{~N}( \pm 0.21)$, expressed as the peak load required to break the joints (maximum force). These values are deemed acceptable for those packaging applications requiring good peelable seals.

\section{Characterization of the optimized sealing coating}

Once the contribution of each individual factor to the selected response was estimated, specific analyses were carried out in order to get more detailed information on the physical phenomenon at the base of the adhesion between the two coated side of the OPP film after 
heat-sealing. To this purpose, coatings of a dry thickness average of $1.51 \mu \mathrm{m} \pm 0.08$ were obtained. Figure 3 shows SEM images collected after rupture of sealed (temperature: $90^{\circ} \mathrm{C}$; dwell time: $1 \mathrm{~s}$; pressure: 4 bar) OPP strips coated according to the selected formulation. Three different zones were clearly visualized, as displayed in $3 \mathrm{a}$, which was captured in topographical mode: 1) the substrate (OPP); 2) the coating initially lied on the upper OPP strip, de-bound from the substrate after rupture; 3 ) the coating initially lied on the lower OPP strip, still bound to the substrate. This configuration allows the mode of failure of the heatsealed joints after rupture to be elucidated. It is likely that two different modes took place during joints separation. Region 3 suggests that the heat-seal failed in peeling mode failure. As it has been pointed out by Yuan and co-workers, ${ }^{31}$ under this failure mode, disentangles and extricates chain ends from the opposite surface occurred, in which the heat-seal bond was peeled apart. In our case, this happened for strength of the seal lower than the adhesion forces at the OPP/coating interface. Conversely, regions 1 and 2 may be explained in terms of tearing mode failure, which is typical of strength of the seal higher than the strength at the substrate/coating interface.

This double behavior has been already cited for polyethylene-based seals done at a temperature range few degrees below the melting point of the thermoplastic molecule, namely at the transition region in which the failure mode turns from peeling to tearing mode failure. ${ }^{31}$ Although in our knowledge this behavior has never been described before for seals originating from biopolymers like gelatin, it is reasonable to think that a combination of both failure modes involved also our coating. This is because also the sealing temperature adopted in this work $\left(90^{\circ} \mathrm{C}\right)$ was slightly lower than the melting temperature of the coating, as supported by the DSC analysis performed on the dried coating (Figure 4), which exhibited a melting temperature of approximately $94^{\circ} \mathrm{C}$. The coexistence of both tearing and peeling modes of failure can be thus explained considering that, at this boundary thermal region, it is unlikely that the thermoplastic macromolecule (i.e., gelatin) undergoes only one discrete physical 
transition. Indeed, it is fairly probable that some domains, in which the amorphous phase prevails, would completely melt (leading to the tearing mode), whereas for other domains (those with a partial crystalline feature) the transition would be only at the beginning (leading to the peeling mode). Neither the effect arising from the corona treatment performed before coating deposition should be underestimated at this juncture. Due to the heterogeneity of the electrical discharge onto the plastic surface, it is plausible that some areas of OPP resulted more suited to bind the biobased coating than those regions where the treatment was less effective.

Finally, the role played by the lipid component is worth to be mentioned. Hydrophobic substances, like paraffin and waxes, are generally used for applications where high bond strengths and heat resistance are not required, but remarkable seal continuity is aimed. Indeed, the addition of such a component makes easier filling any voids that might have appeared onto the substrate, to the detriment of the seal strength, which turns into peelable. ${ }^{32}$ These considerations are in agreement with our observations. Figure 3 a provides an overview on the coating surface, showing that region 2 was smooth and regular, whereas region 3 had a 'moon-like' surface, being clearly visible depressions similar to craters. At first glance, they might be due to the presence of air bubbles formed during the emulsification process that moved from the bulk to the solid-air interface. A deeper investigation suggested the blooming of the phase-separated glycerol and lipid upon the coating deposition. It seems to be confirmed by Figure $3 \mathrm{~b}$, where the darker regions are normally attributed to the lower molecular weight components within a formulation, according to the compositional mode images acquisition.

The presence of particles dispersed within the hydrogel solution is further confirmed by the particle size analysis shown in Figure 5. The coating sample showed two peaks centered at $4.1 \mathrm{~nm}$ and $1354 \mathrm{~nm}$, the latter supposedly due to small drops of phase-separated lipid and glycerol after the emulsification process. The scattering phenomenon of visible light through 
the film is somehow confirmed by UV-Vis spectra of both uncoated and coated polypropylene films (Figure 6). Transparency of the coated films $(86.43 \% \pm 1.7)$ was inferior to that of the neat films $(90.35 \% \pm 0.5)$, although the 'see-through' property of the original films was not affected significantly, as also confirmed by visual inspection. As already pointed out, such 'hazy' effect seem to be due to the morphological inhomogeneity of the coating thickness across the width, since the lipid component in the final formulation is in the form of tiny drops entrapped in the gelatin network (especially after mechanical homogenization). ${ }^{14}$

\section{CONCLUSIONS}

Based upon these present results and those in our previous study, ${ }^{23}$ biomacromolecules such as gelatin, acetylated monoglycerides and a proper plasticizer (e.g., glycerol) show the potential as a sealable coating for many packaging applications. Further, our findings suggest that a new class of coatings may be accurately designed to originate tailored seals, i.e. ranging from weak peelable to hermetic. However, for such a new class of biocoatings to work efficiently, a proper setting of the main parameters (both process and formulation variables) is of utmost importance. At the same time, to implement the scale-up process, further issues should be faced. Among them, quantification of cling of the bioseal surface to the release surface claims particular attention, since rolls of coated plastic films must unwind smoothly on the packaging equipment. Finally, it must be kept in mind that the potential linked to these coatings relies also on the possibility of exploiting them as multifunctional devices. Ongoing works in our team seem to confirm that, for instance, these coatings can be simultaneously used as both sealing layers and natural reservoir of active compounds (e.g., antimicrobials) to be released in the package in a controlled manner under the effect of a selected trigger (e.g., temperature, humidity, etc.).

Acknowledgements: we are thankful to Dr. A. Brun for technical and scientific assistance. 


\section{References}

1. Tracton, A. A. Coatings Technology Handbook, $3^{\text {rd }}$ edition; CRC Press: Boca Ranton, 2006.

2. Lange, J.; Wyser, Y. Packag Technol Sci 2003, 16, 149.

3. Hong, S.-I.; Lee, J.-W.; Son. S.-M. Packag Technol Sci 2005, 18, 1.

4. Bertaux, E.; Le Marec, E.; Crespy, D.; Rossi, R.; Hegemann, D. Surf Coat Technol 2009, 204, 165.

5. Andersson, C.; Järnström, L.; Fogden, A.; Mira, I.; Voit, W.; Zywicki, S.; Bartkowiak, A. Packag Technol Sci 2009, 22, 275.

6. Shi, X.; Nguyen, T. A.; Suo, Z.; Liu, Y.; Avci, R. Surf Coat Technol 2009, 204, 237.

7. Andersson, C. Packag Technol Sci 2008, 21, 339.

8. Chalier, P.; Ben Arfa, A.; Preziosi-Belloy, L.; Gontard, N. J Appl Polym Sci 2007, 106, 611.

9. Liu, L. S.; Finkenstadt, V. L.; Liu, C.-K.; Jin, T.; Fishman, M. L.; Hicks, K. B. J Appl Polym Sci 2007, 106, 801.

10. Farris, S; Schaich, K. M.; Liu, L.; Piergiovanni, L.; Yam, K. Trends Food Sci Tech 2009, 20, 316 .

11. Hong, S.; Krochta, C. M. J Food Sci 2003, 68, 224.

12. Hong, S.; Krochta, C.M. J Food Eng 2006, 77, 739.

13. Lee, J.; Son, S.; Hong, S. J Food Eng 2008, 86, 484.

14. Farris, S.; Introzzi, L.; Piergiovanni, L. Packag Technol Sci 2009, 22, 69.

15. Gällstedt, M.; Brottman, A.; Hedenqvist, M.S. Packag Technol Sci 2005, 18, 161.

16. Elsabee, M. Z.; Abdou, E. S.; Nagy, K. S. A.; Eweis, M. Carbohyd Polym 2008, 71, 187.

17. Apostolov, A. A.; Fakirov, S.; Evstatiev, M.; Hoffmann, J.; Friedrich, K. Macromol Mater Eng 2002, 287, 693. 
18. Gómez-Estaca, J.; Bravo, L.; Gómez-Guillén, M. C.; Alemán, A.; Montero, P. Food Chem 2009, 112, 18 .

19. Balakrishnan, B.; Mohanty, M.; Fernandez, A. C.; Mohanan, P. V.; Jayakrishnan, A. Biomaterials 2006, 27, 1355.

20. Rossi, R. C.; Dias, C. L.; Donato, E. M.; Martins, L. A.; Bergold, A. M.; Fröehlich, P. E. Int J Pharm 2007, 338, 119.

21. Schrieber, R.; Gareis, H. Gelatine Handbook: Theory and Industrial Practice, $1^{\text {st }}$ edition, Wiley-VCH, Weinheim, 2007, p. 1.

22. Kim, S.-J.; Ustunol, Z. J Food Sci 2001, 66, 985.

23. Farris, S.; Cozzolino, C. A.; Introzzi, L.; Piergiovanni, L. Packag Technol Sci 2009, 22, 359.

24. WO 075396 A1 (2008), Mirante srl, S. Farris, L. Piergiovanni, G. Ronchi, R. Rocca.

25. ASTM. Standard practices for producing films of uniform thickness of paint, varnish, and related products on test panels. Designation D823-07. American Society for Testing and Materials.

26. Brown, W. E. Plastic in Food Packaging - Properties, Design and Fabrication, $1^{\text {st }}$ edition; Marcel Dekker: New York, 1992.

27. ASTM. Standard test method for seal strength of flexible barrier materials. Designation F 88M-09. American Society for Testing and Materials.

28. ASTM. Standard test method for transparency of plastic sheeting. Designation D 1746 88. American Society for Testing and Materials.

29. Sobral, P. J. A.; Menegalli, F. C.; Hubinger, M. D.; Roques, M. A. Food Hydrocolloyd $2001,15,423$.

30. Vrentas, J. S.; Duda, J. L. J Appl Polym Sci 1978, 22, 2325.

31. Yuan, C. S.; Hassan, A.; Ghazali, M. I. H.; Ismail, A. F. J Appl Polym Sci 2007, 104, 3736.

John Wiley 15 ' S̄ons, Inc. 
32. Martin, E. L. In The Wiley Encyclopedia of Packaging Technology, $1^{\text {st }}$ edition, M. Bakker, D. Eckroth, Eds.; J. Wiley \& Sons: New York, 1986, p. 451.

John Wiley 16 ' S̄ons, Inc. 


\section{Figure legends}

Figure 1. Schematic exemplification of a gelatin molecule segment.

Figure 2. Strain energy evolution as a function of the different setting conditions of $\mathrm{pH}$, glycerol (\%), and lipid (\%).

Figure 3. SEM images of the heat-sealed interface of OPP strips after rupture: a) topographical mode; b) compositional mode. Coating formulation: $\mathrm{pH}=11$; gelatin 54.05 wt.$\%$; glycerol 40.55 wt.-\%; lipid 5.40 wt.-\%.

Figure 4. DSC heating scan of dried coating. Coating formulation: pH=11; gelatin 54.05 wt.$\%$; glycerol 40.55 wt.-\%; lipid 5.40 wt.-\%.

Figure 5. Size distribution by intensity of the gelatin-based hydrogel solution. Hydrogel solution formulation: $\mathrm{pH}=11$; gelatin $10 \mathrm{wt.-} \%$; glycerol $7.5 \mathrm{wt} .-\%$; lipid $1 \mathrm{wt.} . \%$.

Figure 6. UV-Vis mean spectra of neat and coated OPP. The transmittance values at $550 \mathrm{~nm}$ are displayed. 


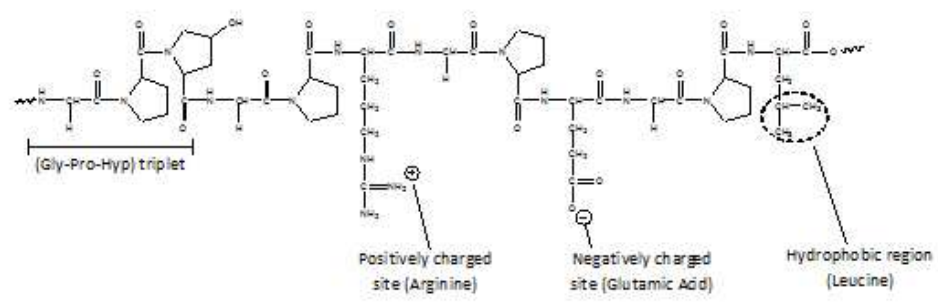

Figure 1. Schematic exemplification of a gelatin molecule segment. $188 \times 58 \mathrm{~mm}(96 \times 96 \mathrm{DPI})$

John Wiley \& Sons, Inc. 


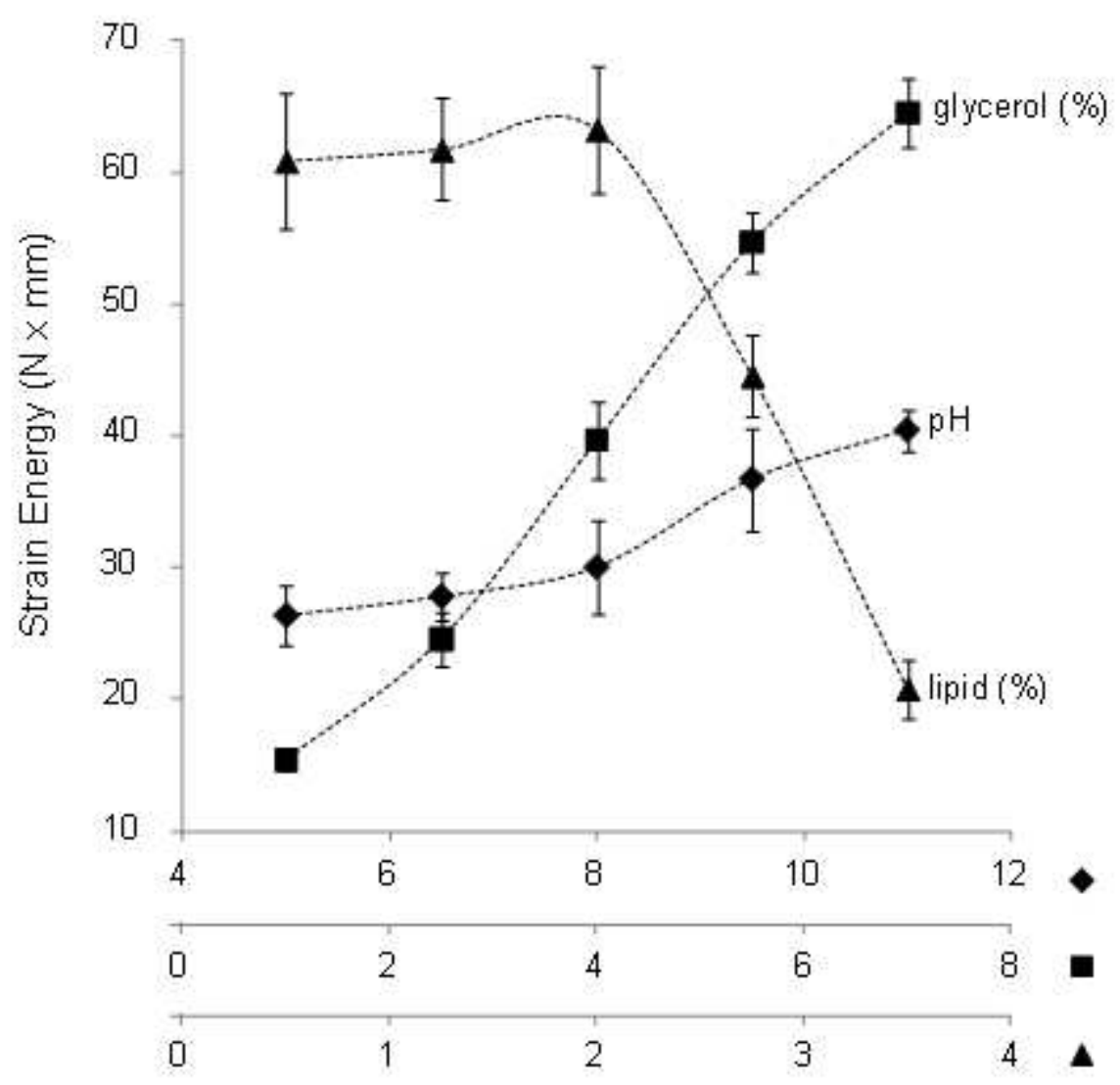

Figure 2. Strain energy evolution as a function of the different setting conditions of $\mathrm{pH}$, glycerol $(\%)$, and lipid (\%). $118 \times 114 \mathrm{~mm}(96 \times 96 \mathrm{DPI})$ 

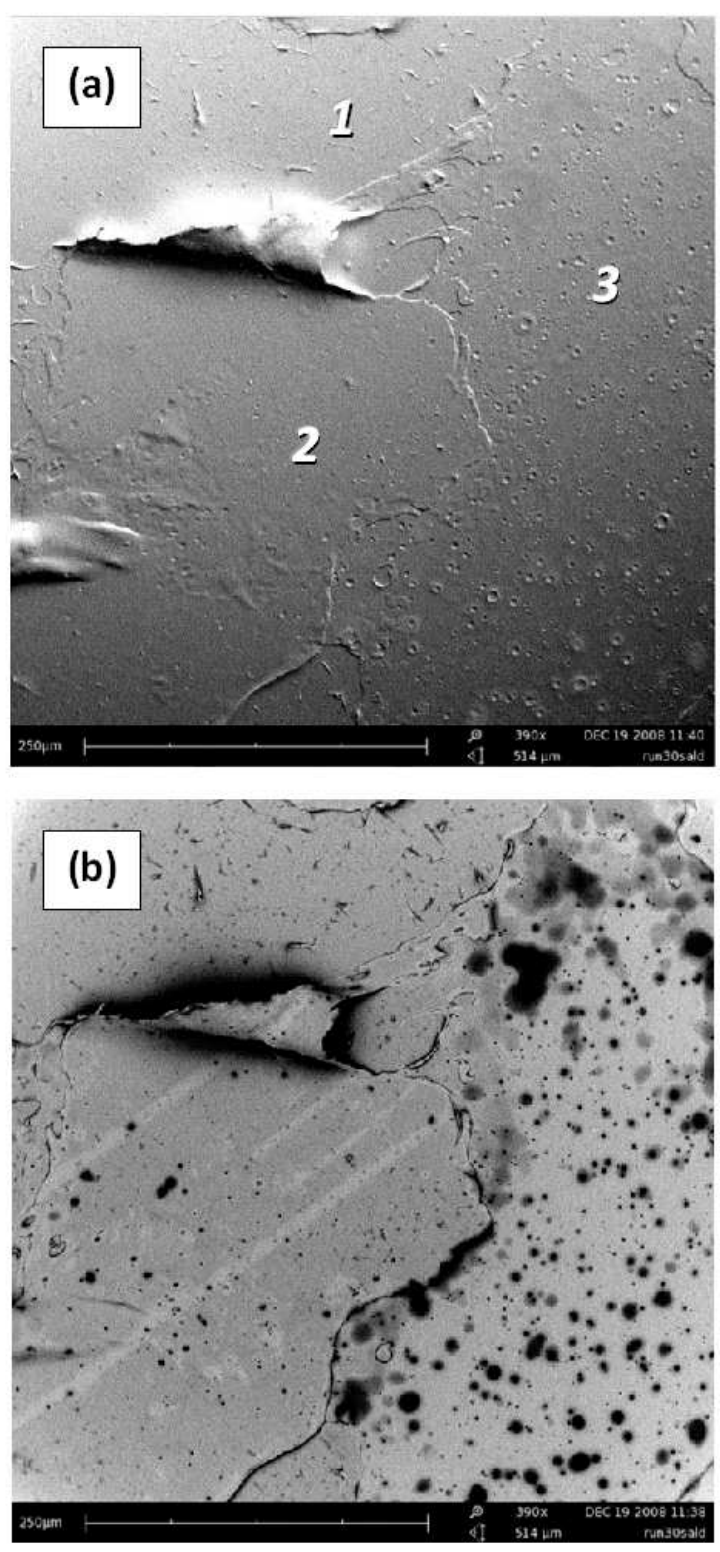

Figure 3. SEM images of the heat-sealed interface of OPP strips after rupture: a) topographical mode; b) compositional mode. Coating formulation: $\mathrm{pH}=11$; gelatin 54.05 wt.- $\%$; glycerol 40.55 wt.-\%; lipid 5.40 wt.- $\%$. $202 \times 268 \mathrm{~mm}(96 \times 96$ DPI $)$ 


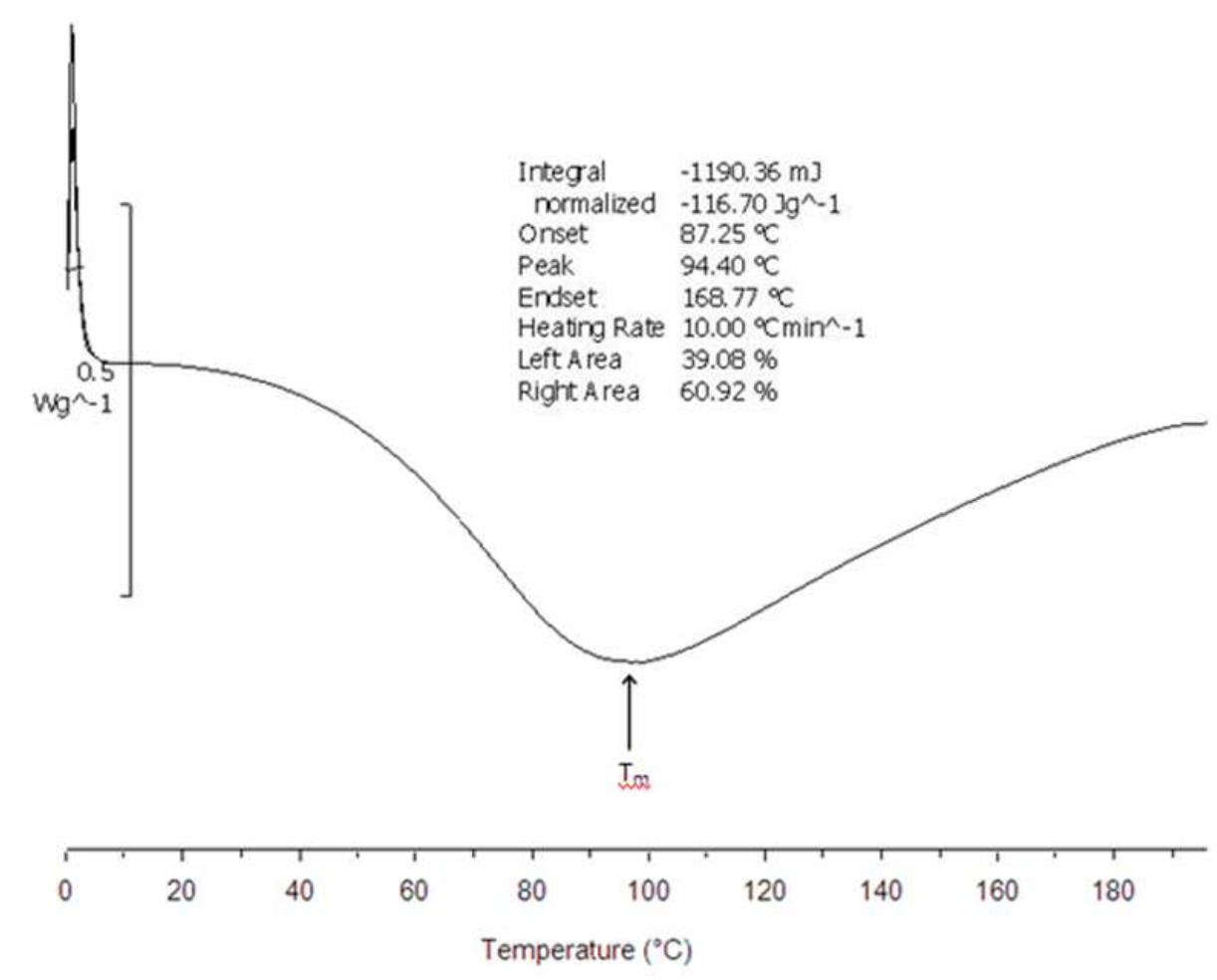

Figure 4. DSC heating scan of dried coating. Coating formulation: $\mathrm{pH}=11$; gelatin 54.05 wt.- $\%$; glycerol 40.55 wt.-\%; lipid 5.40 wt. $-\%$.

$223 \times 175 \mathrm{~mm}$ (96 x 96 DPI)

John Wiley \& Sons, Inc. 


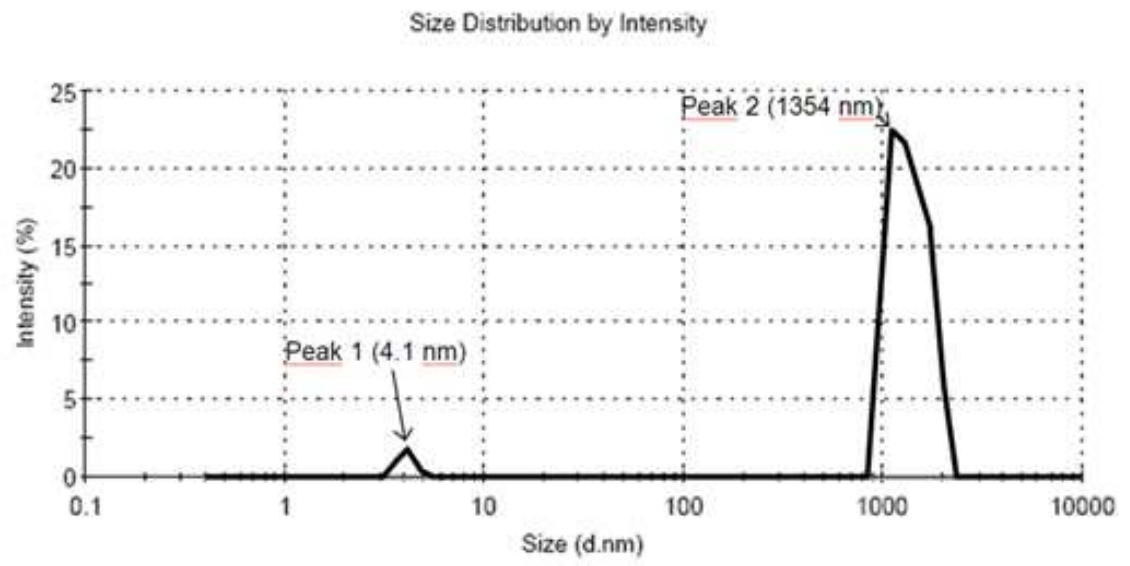

Figure 5. Size distribution by intensity of the gelatin-based hydrogel solution. Hydrogel solution formulation: $\mathrm{pH}=11$; gelatin 10 wt.-\%; glycerol 7.5 wt.-\%; lipid 1 wt.-\%. $157 \times 71 \mathrm{~mm}(96 \times 96 \mathrm{DPI})$ 


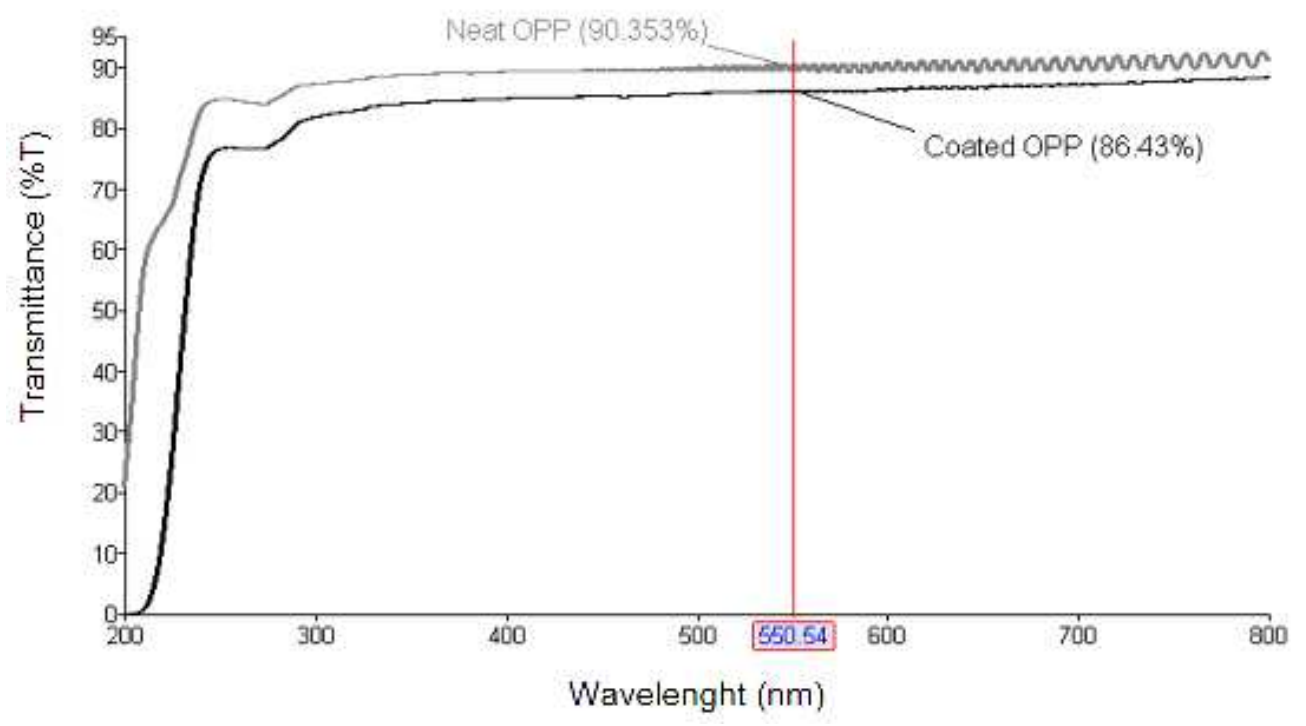

Figure 6. UV-Vis mean spectra of neat and coated OPP. The transmittance values at $550 \mathrm{~nm}$ are displayed.

$146 \times 82 \mathrm{~mm}(96 \times 96 \mathrm{DPI})$

John Wiley \& Sons, Inc. 